\title{
A new Gonatocerus (Hymenoptera: Mymaridae) from Argentina, with taxonomic notes and molecular data on the $G$. tuberculifemur species complex
}

\author{
SERGUEI V. TRIAPITSYN ${ }^{1}$, GUILLERMO A. LOGARZO ${ }^{2}$, JESSE H. DE LEÓN ${ }^{3} \&$ \\ EDUARDO G. VIRLA ${ }^{4}$ \\ ${ }^{1}$ Entomology Research Museum, Department of Entomology, University of California, Riverside, California, 92521, USA. \\ E-mail: serguei.triapitsyn@ucr.edu \\ ${ }^{2}$ USDA, ARS South American Biological Control Laboratory, 3130 Buenos Aires Place, Washington, D.C. 20521-3130, USA. \\ E-mail: glogarzo@speedy.com.ar \\ ${ }^{3}$ Beneficial Insects Research Unit, Kika de la Garza Subtropical Agricultural Research Center, USDA-ARS, 2413 E. Highway 83, \\ Weslaco, Texas, 78596,USA.E-mail: jesus.deleon@ars.usda.gov \\ ${ }^{4}$ CONICET-PROIMI, Avenida Belgrano y Pasaje Caseros, T4001MVB, San Miguel de Tucumán, Tucumán, Argentina. \\ E-mail: evirla@hotmail.com
}

\begin{abstract}
Gonatocerus deleoni Triapitsyn, Logarzo \& Virla sp. n., reared from sentinel eggs of Tapajosa rubromarginata (Signoret) (Cicadellidae: Cicadellinae: Proconiini) on citrus plants, a new member of the ater species group of Gonatocerus Nees (Mymaridae), is described from the state of Mendoza, Argentina. Taxonomic notes and host association data are provided to help differentiate this new species from the morphologically similar but genetically distinct taxon, G. tuberculifemur (Ogloblin). The female of the latter is redescribed and the male is newly described. Gonatocerus deleoni, G. tuberculifemur, and three forms (different molecular clades) comprise the G. tuberculifemur complex. These forms are identified but not formally described because of lack of morphologically distinguishing features. The taxonomic conclusions are supported by molecular data, and by results of reciprocal cross-breeding experiments between most of them.
\end{abstract}

Key words: Mymaridae, Gonatocerus, taxonomy, Cicadellidae, Proconiini, egg parasitoid, Argentina

\section{Introduction}

Gonatocerus Nees is a common and speciose genus of Mymaridae (Hymenoptera), particularly in the Neotropics. Huber (1988) provided an overview of Gonatocerus and defined its species groups. In the New World, many members of the ater species group are known to be egg parasitoids of various proconiine sharpshooters (Hemiptera: Cicadellidae: Cicadellinae: Proconiini) (Triapitsyn 2002a,b, 2006a). During surveys for a neoclassical (i.e., a form of inoculative biological control in which natural enemies are imported from elsewhere and released in small numbers in attempt to establish a permanent population to control a pest with which they have not co-evolved) biological control program against the glassy-winged sharpshooter, Homalodisca vitripennis (Germar), in California, USA, at least 15 species of Gonatocerus were recently reared and identified in Argentina, mostly from sentinel eggs of the proconiine sharpshooter Tapajosa rubromarginata (Signoret) (Jones 2001; Jones, Logarzo, Virla et al. 2005; Logarzo et al. 2005; Pilkington et al. 2005; Triapitsyn et al. 2006, 2007; Logarzo, Triapitsyn \& Virla unpublished data). Among them were specimens very similar morphologically to G. tuberculifemur (Ogloblin), which was originally described from a single specimen collected in Pucará, Neuquén Province, Argentina (Ogloblin 1957). The species, determined during 2001-2006 as G. tuberculifemur [and named below as G. sp. near tuberculifemur "Clade 1", based on a mitochondrial cyto- 